\title{
e-Interview
}

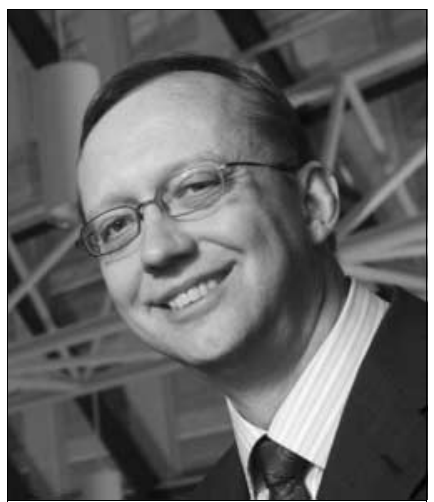

\section{John G. Csernansky}

John G. Csernansky, MD, is Gilman Professor and Chair, Department of Psychiatry and Behavioral Sciences, Northwestern Feinberg School of Medicine and Chair, Department of Psychiatry, Stone Institute of Psychiatry of Northwestern Memorial Hospital. He trained at New York University and Stanford. His special interests include pathogenesis of schizophrenia.

If you were not a psychiatrist, what would you do?

I would probably have become an endocrinologist. I have always been fascinated by the interplay of biology and psychology, and there is much to be learnt from endocrinology about that interface.

What has been the greatest impact of your profession on you personally? I have learnt much about personal courage and commitment by working with patients and families who are battling mental illness to regain control of their lives.

\section{Do you feel stigmatised by your} profession?

At times, but less so in more recent years. As a department chair in a medical school, I have been impressed by growing respect chairs in other disciplines have for our profession and the need they perceive for our services.

What are your interests outside of work? I am an amateur violinist and also enjoy outdoor activities, such as hiking and sailing.
Who was your most influential trainer, and why?

Leo Hollister was my principal mentor and served as the model for my career. He performed the first controlled clinical trial of an antipsychotic drug in the USA and along with a small group of like-minded scientists, ushered in the modern era of treatment for psychiatric disorders.

What job gave you the most useful training experience?

I was the medical director of a 100-bed independent psychiatric hospital, where I was responsible for recruiting and developing professional staff and for the management of the hospital's resources (fiscal and human). I found this experience to be essential as my career progressed and I took on more management responsibilities.

What part of your work gives you the most satisfaction?

I like problem-solving, whether it is in the clinic, the classroom, the laboratory or the boardroom.

\section{What do you least enjoy?}

I do not enjoy conflicts that arise between the various mental health disciplines. For example, there is an ongoing struggle over whether psychologists should be able to prescribe psychotropic medications and however this issue is resolved, I do not think patients benefit from the debate.

What is the most promising opportunity facing the profession?

Although this has been said for some time, I believe that our most promising opportunity is the introduction of new knowledge about neuroscience into the practice of psychiatry. We have been struggling for a few decades now to grasp the complexity of the brain, but we are finally on the threshold of knowing enough to develop reasonable models of the pathophysiology of neuropsychiatric diseases and how to treat them.

\section{What is the greatest threat?}

I worry that the public has become impatient with the progress of biomedical research and will begin to withdraw its support for it. As neuroscientists, we need to do a better job of explaining to the public how research is conducted and how knowledge is accrued. Also, we must deliver clear advances in care that the public can appreciate.

What single change would substantially improve quality of care?

We desperately need to simplify how we pay for mental healthcare. Our present system (in the USA) of managed care and mental health carve outs undermines the care of many individuals with psychiatric illness.

\section{What conflict of interest do you} encounter most often?

As a scientist, you must be prepared to give up your hypothesis if the data demand it. Too often we become too attached to our own theories, despite data that offer evidence to the contrary.

What is the most important advice you could offer to a new trainee?

Be passionate about your career and be prepared for many changes. Over the course of my career, I have seen many theories rise and fall, and I have had the pleasure of working in many different settings and filling different roles. The ability to adapt to change is essential to success.

What are the main ethical problems that psychiatrists will face in the future?

I think the boundary between psychiatric illness and social problems will continue to be murky and unsettling. We have still not determined the proper role of psychiatry at this interface.

What single area of psychiatric practice is most in need of development?

Community-based care for mental illnesses is still underdeveloped despite decades of effort.

What single area of psychiatric research should be given priority?

Clinical trials of new psychotropic drugs are diminishing. Governmental entities, such as the US National Institutes of Health, must step in to stimulate new clinical research in this area, to fill the gap that the shrinking pharmaceutical industry is leaving.

How would you like to be remembered? By my patients as someone who helped them resume their lives.

Dominic Fannon

doi: 10.1192/pb.bp.110.033597 